\title{
THE ASTROGRAPHIC CATALOGUE
}

\author{
A Gold Mine for Proper Motions
}

\author{
D.H.P. JONES \\ Royal Greenwich Observatory, Cambridge, UK
}

\section{Introduction}

The most reliable method of cross-wavelength identification is the coincidence of accurately determined positions, both referred to the same reference frame. But objects move with time and the more accurate their positions, the more important their proper motions are.

\section{The Astrographic Catalogue}

A useful sky survey should cover the whole sky to a uniform flux limit at a given wavelength. The need for such surveys was realized in the 19th century e.g., Bonner Durchmusterung. The earliest whole sky survey of accurate positions was the Astrographic Catalogue and Carte du Ciel planned at a conference in Paris in 1887. Eighteen observatories agreed to collaborate; each would observe a separate band of declination. The aims were

1. To use a common design of telescope with a plate scale of $60.0 \mathrm{~mm}^{-1}$. and a field of $2^{\circ}$.

2. To produce a catalogue of all stars brighter than 11 , accurate to $0 \prime \prime 3 \mathrm{rms}$ in the measured coordinates and 0.5 in Right Ascension and Declination. Exposures of $6 \mathrm{~min}, 3 \mathrm{~min}$ and $20 \mathrm{sec}$ were taken on each plate.

3 . To produce charts reaching to magnitude 14 . With the emulsions then available it was believed that a $40 \mathrm{~min}$ exposure would be needed; most observatories took three exposures in the form of an equilateral triangle.

The number of observatories eventually rose to 22 . Although Greenwich published its catalogue by 1906, the last zone was not published until 1962 . The catalogue has never been widely used because of the inconvenience and inaccuracy of converting the rectangular coordinates to Right Ascension 
and Declination and inhomogeneities between the different zones in limiting magnitude, accuracy and presentation. The published catalogue contains four million stars.

\section{Recent Work}

There has been an upsurge of interest in the Astrographic Catalogue in recent years; (e.g., Röser \& Høg 1993; Urban et al. 1996a, 1996b; Kuzmin, this volume, p. 409). While there are substantial differences between zones, all have limiting magnitudes closer to 12 photographic than the 11 expected. The accuracy differs markedly between different zones, from 0 " 19 to $0^{\prime \prime} 42$ and there is evidence that the difference arises from the methods of measurement which differ from zone to zone. It appears that the plates are essentially homogeneous between zones in accuracy but not in limiting magnitude. If this is confirmed then re-measurement with a modern automatic machine should improve all the zones to the level of the best.

At the 1994 IAU, Commission 24 (de Vegt \& Morrison 1995) set up a new working group to consider the re-measurement of the Astrographic Catalogue.

TABLE 1. Working Group on Re-measuring Astrographic Plates

\begin{tabular}{llll}
\hline Members & Status & Members & Status \\
\hline B Bucciarelli & & S Röser & \\
TE Corbin & & R Smart & (Consultant) \\
CC Dahn & & SE Urban & (Consultant) \\
DHP Jones & (Chairman) & Chr de Vegt & \\
\hline
\end{tabular}

As a pilot study, a plate borrowed from the Vatican Observatory has been re-measured on a conventional PDS. Table 2 shows the goodness of fit when the measures are reduced with the ACRS catalogue and six degrees of freedom. The corrected values have been found by subtracting the ACRS errors quadratically. The goodness of fit is better than 0.19 compared to 0 ".42 for the printed catalogue.

A better estimate of the accuracy of the measures can be found from the difference of the 6 and 3 minute exposures. The Vatican catalogue is based on the $3 \mathrm{~min}$ exposure. The r.m.s. errors of one measurement, listed in Table 3, show a steady increase with machine magnitude. One micron is believed to be the irreducible measuring error and corresponds to 0.06 . If the limiting magnitude is set at 13.5 then an accuracy of 0 "' 18 should result, in accordance with other recent work (Hiesgen, this volume, p. 415; 
TABLE 2. Goodness of fit (r.m.s.) of Vatican Plate

\begin{tabular}{|c|c|c|c|c|}
\hline Exposure & $\alpha$ & $\delta$ & $\alpha(\operatorname{corr})$ & $\delta($ corr $)$ \\
\hline $6 \mathrm{~min}$ & $0 . .28$ & $0 . .23$ & 0.11 & 0.15 \\
\hline $3 \mathrm{~min}$ & $0 . ! 26$ & $0 . ' 26$ & $0 ., 08$ & 0 "' 19 \\
\hline ACRS & $0 . .25$ & 0.18 & & \\
\hline
\end{tabular}

TABLE 3. Accuracy as a function of magnitude

\begin{tabular}{rrrcc}
\hline Magnitude & limits & Number & $\sigma_{x}(\mu)$ & $\sigma_{y}(\mu)$ \\
\hline 8 & 9 & 22 & 0.9 & 1.3 \\
9 & 10 & 46 & 0.9 & 1.3 \\
10 & 11 & 86 & 1.1 & 1.0 \\
11 & 12 & 139 & 1.2 & 1.3 \\
12 & 13 & 229 & 2.1 & 2.0 \\
13 & 14 & 224 & 4.2 & 3.8 \\
\hline
\end{tabular}

Geffert et al. 1996). Continuing problems are caused by the réseau lines which were photographed on to each plate; and the difficulty of defining the centre of a triangle of images which are resolved for faint stars but blended for bright.

\section{References}

de Vegt, Chr. and Morrison, L.V. 1995 WGM 3 International Catalogue Projects, Highlights of Astronomy, 10, pp. 683-695

Geffert, M., Bonnefond, P., Maintz, G. and Guibert, J. 1996 The astrometric accuracy of "Carte du Ciel" plates and proper motions in the field of the open cluster NGC 1647 Astron. Astrophys. Suppl.118, 277

Röser,S. and Høg,E. 1993 Tycho Reference Frame Catalogue (TRC): A Catalogue of Positions and Proper Motions of one Million Stars Workshop on Databases for Galactic Structure,pp. 137-143

Urban, S.E., and Corbin, T.E. 1996a New reductions of the Astrographic Catalogue; Conventional plate adjustment of the Cape Zone Astron.Astrophys.305, 989

Urban, S.E., Martin, J.C., Jackson, E.S. and Corbin, T. E. 1996b New Reductions of the Astrographic Catalogue; Plate adjustments of the Algiers, Oxford I and II, and Vatican Zones Astron. Astrophys. Suppl. 118, 163 